Tropical Journal of Pharmaceutical Research March 2019; 18 (3): 591-595

ISSN: $1596-5996$ (print); 1596-9827 (electronic)

(C) Pharmacotherapy Group, Faculty of Pharmacy, University of Benin, Benin City, 300001 Nigeria.

\title{
Effect of ethanol extract of Punica granatum L against Freund's complete adjuvant-induced arthritis in rats
}

\author{
Yanming Wang, Tao He, Zhiming Li* Shujun Gai \\ Department of Orthopedic Surgery, Dezhou People Hospital, Dezhou, Shandong 253014, China \\ *For correspondence: Email: LFunderburtise@yahoo.com; Tel: 0086-0534-2265515
}

Sent for review: 20 January 2019

Revised accepted: 21 February 2019

\begin{abstract}
Purpose: To investigate the protective effect of ethanol extract of $P$. granatum against arthritis in rat model.

Methods: Twenty-six adult male Wistar rats $(120$ - $150 \mathrm{~g})$ were separated into four groups $(n=6)$ : normal control, arthritic control and two treatment groups. With the exception of normal control group, arthritis was induced by intraplantar administration of Freund's complete adjuvant (FCA) on the 1st day of drug administration. The arthritic control group was not treated, while the treatment groups received extract orally at 500 or $750 \mathrm{mg} / \mathrm{kg}$ for the period of 4 weeks and at the end of each week, paw volume, thermal hyperalgesia, arthritic score and mechanical nociceptive threshold were performed to assess arthritis. Biochemical indicators and inflammatory cytokines in serum were determined using standard procedures.

Results: There was significant decrease in paw volume and arthritic score; paw withdrawal latency was enhanced in extract-treated groups, compared to arthritic control group $(p<0.05)$. Furthermore, ALT, AST and ALP levels, as well as RF and MDA activities decreased significantly with extract treatment, compared with arthritic control group $(p<0.05)$. Treatment with the extract attenuated the altered level of interleukin $1 \beta$ (IL-1 $\beta)$ and TNF- $\alpha$ levels in arthritic rats. Histological examination showed that treatment with the extract significantly reversed histological changes induced by arthritis.

Conclusion: The results reveal that the beneficial effect of ethanol extract of $P$. granatum against FCAinduced arthritis is due to its ability to reduce the levels of inflammatory cytokines.
\end{abstract}

Keywords: Punica granatum, Rheumatoid arthritis, Cytokines, Enzymes, Inflammation

\begin{abstract}
This is an Open Access article that uses a funding model which does not charge readers or their institutions for access and distributed under the terms of the Creative Commons Attribution License (http://creativecommons.org/licenses/by/4.0) and the Budapest Open Access Initiative (http://www.budapestopenaccessinitiative.org/read), which permit unrestricted use, distribution, and reproduction in any medium, provided the original work is properly credited.
\end{abstract}

Tropical Journal of Pharmaceutical Research is indexed by Science Citation Index (SciSearch), Scopus, International Pharmaceutical Abstract, Chemical Abstracts, Embase, Index Copernicus, EBSCO, African Index Medicus, JournalSeek, Journal Citation Reports/Science Edition, Directory of Open Access Journals (DOAJ), African Journal Online, Bioline International, Open-J-Gate and Pharmacy Abstracts

\section{INTRODUCTION}

Rheumatoid arthritis (RA) is an autoimmune disorder which affects about $1 \%$ of the world's population [1]. It is a systemic, inflammatory, symmetric and chronic disorder characterized by rheumatoid pannus and articular inflammation which leads to destruction of bones and cartilages [2,3]. Although the pathogenesis of RA has not been fully elucidated, it is believed to be caused by immune reaction in the synovial joint due to persistent infection of the joint [4]. Early symptoms of RA include pain and swelling around the joint and joint dysfunction, while the late stage of the disease is accompanied by disability and bone damage as a result of joint 
deformity and stiffness [5]. Anti-inflammatory and analgesic drugs used in the treatment of RA serve as mere palliatives. Anti-CD20 and antiTNF- $\alpha$ therapiesare used to control immune responses in RA [6,7]. At present, drugs used for treating RA produce serious side effects. Therefore, the use of alternative medicine for long-term management of RA has a great prospect.

Punica granatum L, also known as pomegranate, is a fruit-bearing deciduous shrub in the family Punicaceae, and it is used traditionally for the management of several diseases [8]. Extracts of $P$. granatum have been shown to possess immunomodulatory, antioxidant, antifungal, bactericidal and estrogenic activities [9-12]. However, the effect of $P$. granatum extract on RA has not been reported.

The aim of present investigation was to determine the beneficial effect of extract of $P$. granatum against arthritis.

\section{EXPERIMENTAL}

\section{Experimental rats}

Male albino wistar rats weighing (120 - $150 \mathrm{~g})$ were purchased from Shangai Animal House, China. Animals were stored as per the guideline (Humidity: $48 \%$; Temperature: $25^{\circ} \mathrm{C}$ and $12 \mathrm{~h}$ light/dark cycles). Study on the animal performed in the study was approved by the Institutional Animal Ethical Committee of Dezhou People Hospital, China (approval no. $\mathrm{DPH} / \mathrm{IAEC} / 2017 / 02)$ and followed the guidelines of Association for the Assessment and Accreditation of Laboratory Animal Care International [13].

\section{Preparation of plant extract}

The peels of $P$. granatum were obtained from a local vendor, shade-dried and then pulverized using an electric blender. A portion of the powder $(150 \mathrm{~g})$ was exhaustively extracted with $400 \mathrm{ml}$ of absolute ethanol in a soxhlet apparatus. Vacuum rotatory evaporator was used to concentrate the extract, and the resultant concentrate was freeze-dried by lyophilization.

\section{Experimental design}

Twenty-six adult male Wistar rats were separated into four groups $(n=6)$ : normal control, arthritic control group and two treatment groups. With the exception of normal control group, arthritis was induced in the rats using Freund's complete adjuvant $(0.1 \mathrm{ml})$ which was injected on the first day of treatment in the intraplantar region of the left hind paws of the rats. Inactivated Mycobacterium tuberculosis (10 mg) was dried in $1 \mathrm{ml}$ of paraffin oil for the preparation of Freund's complete adjuvant. The arthritic control group was not treated, while the treatment groups received 500 or $750 \mathrm{mg} / \mathrm{kg}$ bwt extract/day p.o. for 28 days.

\section{Assessment of the development of arthritis}

Development of arthritis was assessed in the rats by paw volume, thermal hyperalgesia, arthritic score, mechanical nociceptive threshold on days $0,7,14,21$ and 28 of treatment using a plethysmometer. Arthritis score was determined as per the reported method [14].

\section{Collection of blood and tissue samples}

After 4 weeks of treatment, rats were anesthetized and collection of blood was performed from retro-orbital plexuses. Serum was separated out by centrifuging the blood for $10 \mathrm{~min}$ at $3000 \mathrm{rpm}$ for biochemical analyses. The rats were euthanized by cervical dislocation and their ankle joints were excised for histopathological examination.

\section{Biochemical analysis}

Serum activity of alanine amino transaminase (ALT), Aspartate aminotransferase (AST), alkaline phosphatase (ALP), malondialdehyde (MDA) and arthritis factor (RF) were estimated using their respective assay kits, while the levels of TNF- $\alpha$ and IL-1 $\beta$ were assessed by using ELISA kits.

\section{Tissue histology}

Histological examination of the right hind limb was performed using hematoxylin and eosin $(\mathrm{H}$ \& E) staining. Histopathological changes were assessed based on the degree of inflammatory cell infiltration, underlying bone destruction and articular cartilage damage. The extent of cartilage damage was also determined using Mankin score.

\section{Statistical analysis}

Data are represented as mean $\pm S D$, and the Graph Pad Prism (6.1) software was used for the statistical analysis. Groups were compared using Dunnett's post hoc multiple test range. Statistically significance considered for the value having $p<0.05$. 


\section{RESULTS}

\section{$P$. granatum extract ameliorates the development of RA}

There were significant increases $(p<0.05)$ in paw swelling and arthritic score, and significant decrease in paw withdrawal latency in arthritic control group than normal control group. However, after treatment with the extract, changes in these parameters were significantly and dose-dependently reversed (Figure 1).
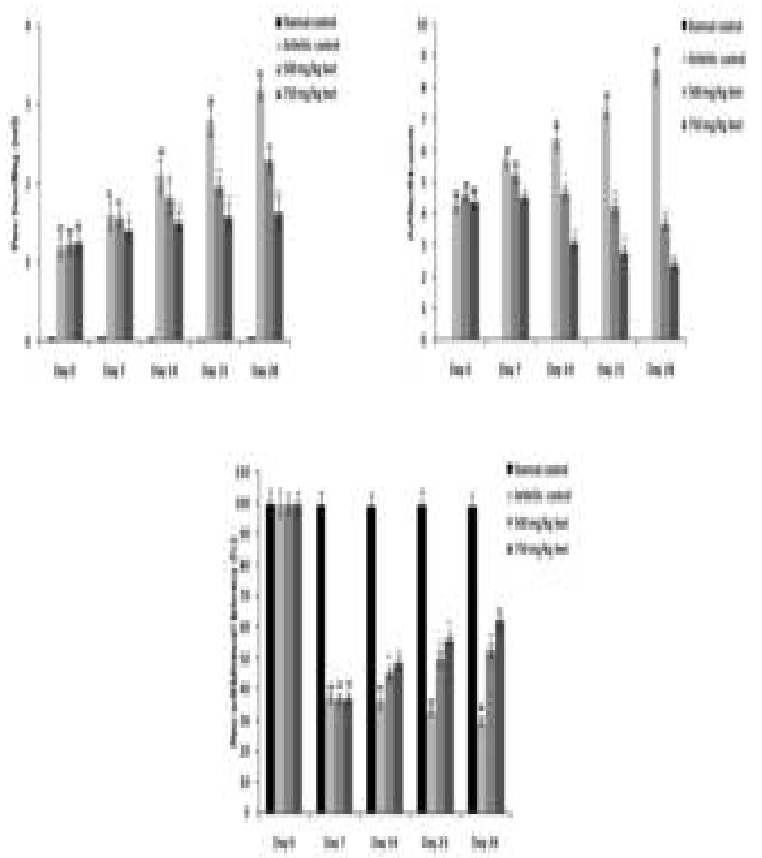

Figure 1: Extract of $P$. granatum attenuates paw swelling, paw withdrawal latency and arthritic score in the rats. $P<0.05$, than normal control group; ${ }^{* \star} p<$ 0.05 , than arthritic control group

\section{Effect of $P$. granatum extract on the levels of some marker enzymes, RF and MDA}

The activity of marker enzymes and values of RF and MDA were enhanced in arthritic control group than to normal control group. However, treatment with the drug attenuates the altered levels of these parameters in arthritis rats (Table 1).
Effect of ethanol extract of $P$. granatum on levels of inflammatory cytokines

Figure 2 shows that the levels of TNF- $\alpha$ and IL$1 \beta$ were significantly enhanced up to 431 and $810 \mathrm{pg} / \mathrm{ml}$ respectively in arthritic control group, but were significantly and dose-dependently reduced $(p<0.05)$ after treatment with extract.
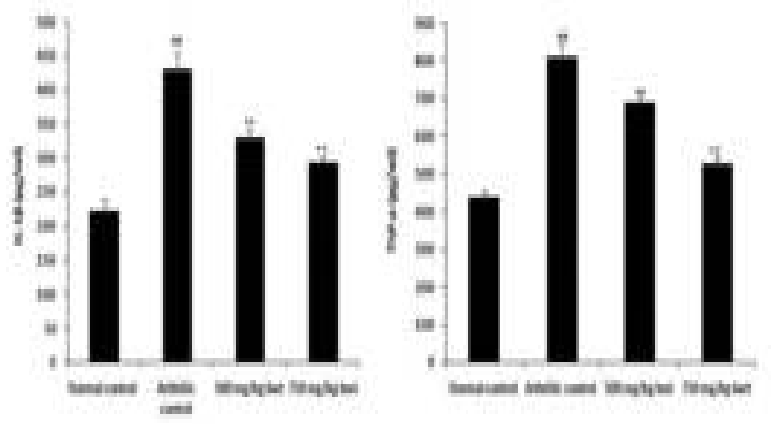

Figure 2: Effect of ethanol extract of $P$. granatum on serum levels of inflammatory cytokines. ${ }^{\# \#} P<0.05$ than normal control; ${ }^{* \star} p<0.05$ than arthritic control

\section{Effect of ethanol extract of $P$. granatum on histology of knee joint}

Tissue section of knee joint of normal control rats revealed clearly visible articular cavity and smooth articular cartilage surface without pathological alteration or infiltration of inflammatory cells in the synovium. However, histopathological changes such as hyperplasia of capillary, infiltration of inflammatory cells, changes in the structure of sub-synovial collagen fiber and thickening of extracellular matrix were observed in the arthritic control group.

The pathological changes induced by RA were markedly mitigated on treatment of the arthritic rats with ethanol extract of $P$. granatum. Results of Mankin score showed that the extract significantly mitigated cartilage damage caused by arthritis. Bone destruction and infiltration of inflammatory cells were significantly alleviated in extract-treated groups than arthritic control group (Figure 3).

Table 1: Extract of $P$. granatum attenuates some marker enzymes and MDA level in arthritis rats

\begin{tabular}{lccccc}
\hline Group & ALT(U/L) & AST (U/L) & ALP (U/L) & MDA (nmol/ml) & RF (IU/ ml) \\
\hline Normal control & $43.72 \pm 3.16$ & $41.48 \pm 2.17$ & $79.23 \pm 3.61$ & $3.16 \pm 0.21$ & $0.00 \pm 0.00$ \\
Arthritic control & $181.40 \pm 11.83^{\mathrm{a}}$ & $147.33 \pm 12.29^{\mathrm{a}}$ & $437.3 \pm 23.10^{\mathrm{a}}$ & $7.59 \pm 0.37^{\mathrm{a}}$ & $86.94 \pm 3.72^{\mathrm{a}}$ \\
$500 \mathrm{mg} / \mathrm{kg}$ extract & $139.60 \pm 6.26^{\mathrm{ab}}$ & $113.27 \pm 9.12^{\mathrm{ab}}$ & $329.1 \pm 14.70^{\mathrm{ab}}$ & $6.28 \pm 0.27^{\mathrm{ab}}$ & $47.31 \pm 2.42^{\mathrm{ab}}$ \\
$750 \mathrm{mg} / \mathrm{kg}$ extract & $93.71 \pm 7.29^{\mathrm{abc}}$ & $89.38 \pm 4.91^{\mathrm{abc}}$ & $186.4 \pm 11.30^{\mathrm{abc}}$ & $4.49 \pm 0.23^{\mathrm{abc}}$ & $29.73 \pm 1.33^{\mathrm{abc}}$ \\
\hline \multicolumn{4}{c}{$P<0.05$ than normal control group; ${ }^{\mathrm{b}} p<0.05$ than arthritic control group; ${ }^{\mathrm{c}} p<0.05$ than $500 \mathrm{mg} / \mathrm{kg} \mathrm{group}$}
\end{tabular}




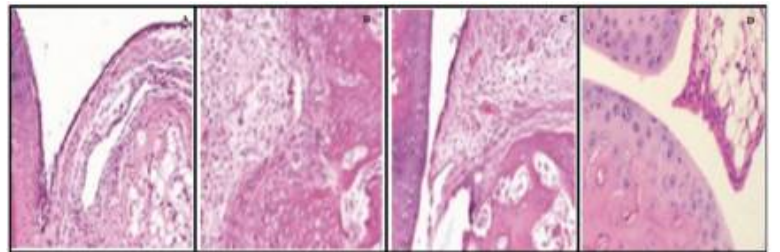

(I)

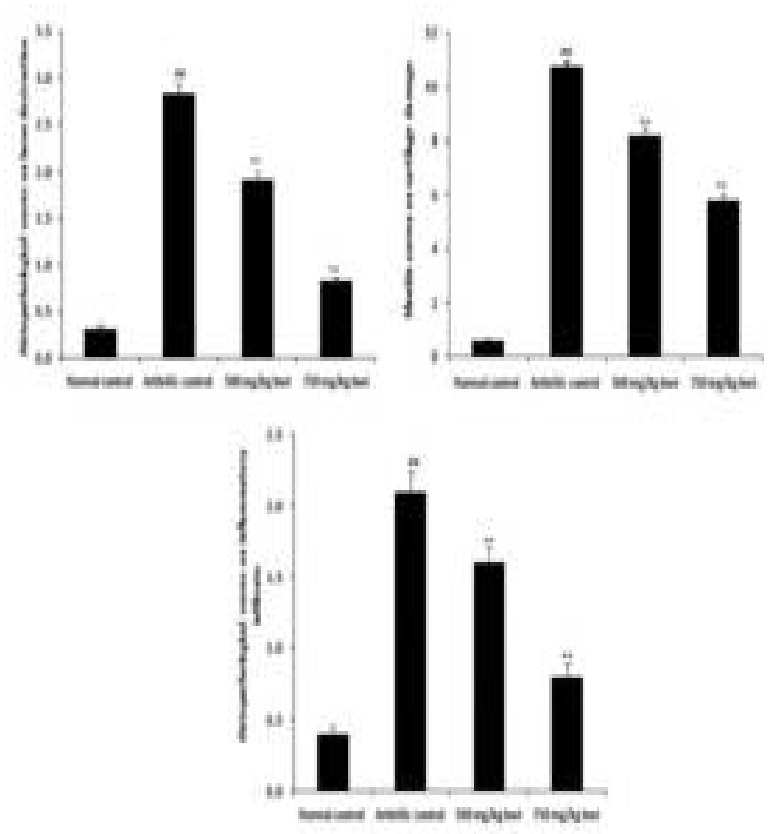

(II)

Figure 3: Effect of ethanol extract of $P$. granatum on the histology of knee joints of the rats. I: Photomicrographs of tissue sections. A: Normal control group; B: Arthritic control; C: $500 \mathrm{mg} / \mathrm{kg}$ bwt group; and D: $750 \mathrm{mg} / \mathrm{kg}$ bwt group. II. Histopathological scores for bone destruction, cartilage damage and inflammatory infiltrate. ${ }^{\# \#} P<$ 0.05 than normal control; ${ }^{* *} p<0.05$ than arthritic control

\section{DISCUSSION}

Rheumatoid arthritis is an autoimmune disorder of joint with the symptom of cartilage deterioration \& inflammation of synovium [2]. Symptoms of RA include dyskinesia and arthralgia of limb joint.

Autoimmunity may occur as a result of imbalance between humoral immunity and cellular immunity [15]. The levels of inflammatory cytokines are significantly elevated in cellular immunity when compared with humoral immunity [16]. Circulatory cytokines in the synovium are one of the parameter contribute in the development of $\mathrm{RA}$ [17].

The present study investigated the protective activity of ethanol extract of $P$. granatum in FCA induced arthritis in rats. The results showed that there were significant increases in swelling in paw \& arthritic score, and significant decreases in paw withdrawal latency in arthritic control group, when compared with the normal control group. However, after treatment with the extract, changes in these parameters were significantly and dose-dependently reversed.

Arthritis is characterized mainly by swelling of the synovium due to the proliferation of synovial cells, and it has been reported that serum activities of ALP, ALT and AST are elevated in arthritis due to hepatic lesions [18]. These enzymes are used as markers for the localization of bone loss in bone resorption and formation [19]. Malondialdehyde (MDA) is an important index of lipid peroxidation since most diseases are accompanied by elevated MDA levels. In this study, the activity of ALP, AST \& ALT, and values of RF and MDA were significantly higher in arthritic control group than in normal control group. However, treatment with the extract significantly and dose-dependently reduced the activities and levels of these parameters.

Cytokines are involved in the pathogenesis of $R A$ [20]. They increase erosion of bone, degradation and destruction of articular cartilage, and inflammation. Anti-inflammatory drugs used in the management of arthritis reduce the production of cytokines. It has been reported that the expression of TNF- $\alpha$ is significantly upregulated in arthritic mice [21]. In RA, inflammatory cytokines inhibit the synthesis of bone, stimulate osteoclastic action and destroy cartilage collagen. In this study, the levels of IL$1 \beta$ and TNF- $\alpha$ were significantly increased in the arthritic control group, relative to normal control group, but were significantly and dosedependently reduced after treatment with the extract. Histopathological examination also showed that treatment with the extract significantly reversed histological changes induced by arthritis.

\section{CONCLUSION}

The findings of this study that the protective effect of the ethanol extract of $P$. granatum against arthritis is due to its ability to reduce the levels of inflammatory cytokines.

\section{DECLARATIONS}

\section{Acknowledgement}

The authors wish to specially thank Dezhou People Hospital, China, for providing funds and laboratory facilities for this work. 


\section{Conflict of interest}

No conflict of interest is associated with this work.

\section{Contribution of authors}

We declare that this work was done by the authors named in this article and all liabilities pertaining to claims relating to the content of this article will be borne by the authors. Yanming Wang and Tao He has done the experimental work and contributed equally for the presented work. Zhiming Li designed and supervises the work and writes the manuscript, Shujun Gai performed statistical analysis for this work.

\section{REFERENCES}

1. Coiffier G, Bouvard B, Chopin F, Biver E, Funck-Brentano T, Garnero P, Guggenbuhl P. Common bone turn over markers in rheumatoid arthritis and ankylosing spondylitis: a literature review. Joint Bone Spine, 2013; 80: 250-257.

2. Wang $Q$, Kuang $H$, Su $Y$, Feng J, Guo $R$, Chan $K$. Naturally derived anti-inflammatory compounds from Chinese medicinal plants. J Ethnopharmacol, 2013; 146 : 9-39.

3. Huffman KM, Jessee R, Andonian B, Davis BN, Narowski R, Huebner JL, Kraus VB, McCracken J, Gilmore BF, Tune KN, Campbell M, Koves TR, Muoio DM, Hubal MJ, and Kraus WE. Molecular alterations in skeletal muscle in rheumatoid arthritis are related to disease activity, physical inactivity, and disability. Arthritis Res Ther, 2017; 19: 12.

4. Hair MJH, Sande MGH, and Ramwadhdoebe, TH. Features of the synovium of individuals at risk of developing rheumatoid arthritis: implications for understanding preclinical rheumatoid arthritis, Arthritis Rheumatol, 2014; 66: 513-522.

5. Walsh DA and McWilliams DF. Mechanisms, impact and management of pain in rheumatoid arthritis. Nat Rev Rheumatol., 2014; 10: 581-592.

6. Schiff $M$, Keiserman $M$, Codding $C$, Songcharoen $S$, Berman A, Nayiager S, Saldate $C$, Aranda R, Becker JC, Nys M, le Bars M, Reed DM, Poncet C, Dougados $M$. Clinical response and tolerability to abatacept in patients with rheumatoid arthritis previously treated with infliximab or abatacept: Open-label extension of the ATTEST Study, Ann Rheum Dis, 2011; 70: 2003-2007.

7. Harmse $L$ and Reuter $H$. An overview of the biological disease modifying drugs available for arthritic conditions in South Africa. S Afr Fam Pract, 2016; 58: 6-10.

8. Jurenka JS. Therapeutic applications of pomegranate (Punica granatum L.): a review. Altern Med Rev. 2008; 13: 128-144.
9. Lansky EP, Newman RA. Punica granatum (pomegranate) and its potential for prevention and treatment of inflammation and cancer, $J$ Ethnopharmacol. 2007; 109: 177-206.

10. Ismail T, Sestili P, Akhtar S. Pomegranate peel and fruit extracts: a review of potential anti-inflammatory and anti-infective effects, J Ethnopharmacol. 2012; 143: 397-405.

11. Larrosa M, González-Sarrías A, Yáñez-Gascón MJ, Selma MV, AzorínOrtuño M, Toti S, Tomás-Barberán F, Dolara P, Espín JC. Anti-inflammatory properties of a pomegranate extract and its metabolite urolithin- $A$ in a colitis rat model and the effect of colon inflammation on phenolic metabolism, J Nutr Biochem 2010; 21: 717725.

12. Satpathy S, Patra A, Purohit A. Estrogenic activity of Punica granatum L. peel extract, Asian pac $j$ reprod, 2013; 2: 19-24.

13. Guide for the Care and Use of Laboratory Animals: Eighth Edition Committee for the Update of the Guide for the Care and Use of Laboratory Animals; National Research Council. 2010; ISBN: 0-309-15401-4.

14. Hegen M, Keith JC Jr, Collins M, Nickerson-Nutter CL. Utility of animal models for identification of potential therapeutics for rheumatoid arthritis. Ann Rheum Dis. 2008; 67(11): 1505-1515.

15. Boissier M C, Assier E, Falgarone $G$, and Bessis $N$. Shifting the imbalance from Th1/Th2 to Th17/treg: The changing rheumatoid arthritis paradigm, Joint Bone Spine, 2008; 75: 373-375.

16. Burmester GR, Feist E, and D"orner T. Emerging cell and cytokine targets in rheumatoid arthritis, Nat Rev Rheumatol, 2014; 10: 77-88.

17. Hu F, Mu R, Zhu J, Shi L, Li Y, Liu X, Shao W, Li G, Li M, Su Y, Cohen PL, Qiu X, Li Z. Hypoxia and hypoxiainduciblefactor-1a provoke toll-like receptor signallinginduced inflammation in rheumatoid arthritis, Ann Rheum Dis, 2014; 73: 928-936.

18. Zhao J, Liu T, Xu F, You S, Li C and Gu Z. Anti-arthritic effects of total flavonoids from Juniperus sabina on complete freund's adjuvant induced arthritis in rats. PharmacognMag, 2016; 12: 178-183.

19. Pan T, Cheng T, Jia Y, Li P, and Li F. Anti-rheumatoid arthritis effects of traditional Chinese herb couple in adjuvant induced arthritis in rats. J Ethnopharmaco, 2017; 205: 1-7.

20. Solomon DH, Curtis JR, Saag KG, Lii J, Chen L, Harrold $L R$, Herrinton LJ, Graham DJ, Kowal MK, Kuriya B, Liu L, Griffin MR, Lewis JD, Rassen JA. Cardiovascular risk in rheumatoid arthritis: comparing tnf- $\alpha$ blockade with non-biologic DMARDs, Am J Med Sci, 2013; 126: 730.e9-730.e17.

21. Ouyang $W$, Kolls JK, and Zheng Y. The biological functions of $T$ helper 17 cell effector cytokines in inflammation. Immunity, 2008; 28: 454-467. 